studied are identical in all cases. There are numerous procedural and perhaps pstchological differences in their use. Moreover. under the stimulus conditions for producing context effects (e.g.. Krantz \& Campbell. 1961: Schiffman et al. 1970). differences in the response mode are significant. This suggests that there may be complexities within each mode that the present procedure has not uncovered. However. it is reasonable to conclude from the present study that the choice of response mode. when experimental conditions are similar to the present one. can be primarily determined by the demands of the experimental design and apparatus. For example. in cases where latency of response measures are recorded. where lighting or visual cues are degraded. or where reports of extensive distances are required (e.g., Gibson. Bergman. \& Purdy. 1955: Ferris, 1972). it is more efficient. practical, and perhaps necessary to employ an absolute estimate mode. In contrast, where research focus is on the relation between two stimuli or in the case where use of a standard-size stimulus is a requisite to comparisons between a series of stimuli (as with geometric illusions). a matching technique should be employed. Generalizing from the stimuli and procedures described herein. the basic results obtained by both response modes would be comparable.

\section{REFERENCES}

Baird. J. C. Retinal and assumed size cues as determinants of size and distance perception. Journal of Experimental Psychology. 1963, 66, 155-162.

Bolles, R. C.. \& Bailey, D. E. Importance of object recognition in size constancy. Journal of Experimental Psychology. 1956. $51,222-225$
Churchill. A. V. Effect of mode of response on judgment of familiar size. Journal of Experimental Psychology. 1962.64. $198-199$

Colhart. M. Effects of two kinds of distance information on visual judgments of absolute size. Nature, 1969. 221. 383.

Epstein. $W$. Perceived depth as a function of relative height under three background conditions. Journal of Experimental Psychology, 1966, 72, 335-338.

Ferris. S. H. Motion parallax and absolute distance. Journal of Experimental Psychology. 1972, 95, 258-263.

Fillenbaum. S.. Schiffman. H. R.. \& Butcher. J. Perception of off-size versions of a familiar object under condition of rich information. Journal of Experimental Psychology, 1965, 69. 298-303.

Garner. W. R., \& Hake, H. W. The amount of information in absolute judgments. Psychological Review, 1951, 58, 446-459.

Gibson, E. J. Bergman, R \& Purdy, J. Effect of prior training with a scale of distance and absolute and relative judgments of distance over ground. Journal of Experimental Psychology. $1955,50.97-105$.

Gogel, W. C., \& Newton, R. E. Perception of off-sized objects. Perception \& Psychophysics, 1969, 5. 7-9.

Krantz, D. L., \& Campbell, D. T. Separating perceptual and linguistic affects of context shifts upon absolute judgments. Journal of Experimental Psvchology, 1961.62.35-42.

Leibowitz. H. W.. \& Hariey, L. O. The effect of instructions. environment, and type of test object on matched size. Journal of Experimental Psychology. 1969, 81, 36-43.

McKennell. A. C. Visual and familiar size: Individual differences. British Journal of Psvchology, 1960,51.27-35.

Miller, C. A., \& Engen. T. Context effects on absolute judgments of length. Journal of Experimental Psychology, 1960, 59 . 276-277.

Over, R. Size and distance estimates of a single stimulus under different viewing conditions. American Journal of Psychology. 1963, 76, 452-457.

Schiffman. H. R. Size-estimation of familiar objects under informative and reduced conditions of viewing. American Journal of Psychology. 1967. 80, 229-235.

Schiffman, J. R.. Goldstein. J., \& E. Aroksaar, R. Response language and context effects. Psychonomic Science, 1970. 20, $127-128$.

Slack. C. W. Familiar size as a cue to size in the presence of conflicting cues. Journal of Experimental Psychology. 1956, 52. $194-198$

(Received for publication July 16. 1973.)

\title{
The effect of frequency and number of pairs in a verbal discrimination task*
}

\author{
SLE SAVAGE and N. JACK KANAK: \\ Lniversity of Oklahoma. Vorman. Okla. 73069
}

The assumption, derived from the frequency theory of verbal discrimination learning, that list length does not affect verbal discrimination learning proficiency was tested. Results indicated that (a) the number of correct items to be learned does affect learning proficiency significantly when the differential frequency cue is held constant; (b) previous findings reported by Ekstrand, Wallace, and Underwood (1966), that a 20-pair list involving 10 right items repeated twice is superior to a

\footnotetext{
* A paper based on the present study was read by the senior author at the Annual Meeting of the Oklahoma State Psychological Association. Oklahoma City, November 1971, and was awarded first prize in the graduate student competition. This research was supported in part by the Faculty Research Fund of the University of Oklahoma.

$\div$ Requests for reprints should be addressed to $\mathrm{N}$. Jack Kanak. Department of Psychology. University of Oklahoma. Norman. Okla. 73069
}

20-pair control group with no repeated items, may have been due, at least in part, to the fewer number of items to be learned and not solely to the larger differential frequency cue.

The frequency theory (Ekstrand. Wallace. \& Underwood. 1966) of verbal discrimination (VD) learning maintains that $S$ learns a VD list by means of the cue provided by differential frequency unit accruals to intrapair right $(\mathrm{R})$ and wrong $(\mathrm{W})$ items. That is. $\mathrm{S}$ pronounces and rehearses the $R$ item more than the $W$ item. thereby building up an intrapair subjective frequency differential in favor of the $R$ item. As Ekstrand et al point out. the frequency theory predicts that increasing the number of pairs in a VD list should have no effect on the number of trials required to learn the lists. provided that an increase in list length is not accompanied by an increase in the number of interitem associations. 
Although the latter assumption is admittedly difficult to control. Lnderwoud. Shaughnessy. \& Zimmerman $(1972)$ did find that a 45 -pair VD list was significantly. more difficult than a 15 -pair list. even on the first of three trials. The materials were extremely low Thorndike-Lorge frequency words. which presumably would allow little opportunity for the development of interitem associations on a single study trial preceding the first test trial. The present study represents an additional test of the list length hypothesis using highly familiar words and was also designed to investigate a related question arising from the Ekstrand et al study. involving the effects of the number of $R$ items to be learned.

In the Ekstrand et al study. a same-right (SR) group involving 20 pairs. with each $R$ item appearing twice and with 20 distinct $W$ items. was found to be superior to a control group of 20 pairs with no repeated items. The superiority of the SR group was attributed to the larger frequency differential accompanying repeated items. but an alternative interpretation is allowed by the fact that the SR group had only $10 \mathrm{R}$ items to recognize v's 20 for the control group. The present study attempts to separate these factors in order to determine whether the total number of $\mathrm{R}$ items to be recognized or the total number of pairs to be discriminated best accounts for the results of Ekstrand et al. independently of the frequency differential between $\mathrm{R}$ and $\mathrm{W}$ items.

Four conditions were employed. two of which were exact replications of the Ekstrand et al SR and control (C-1) 20-pair lists. which were assumed to involve 4:1 and 2:1 frequency ratios, respectively. A second control condition (C-2) of 10 pairs was formed by a random selection of 10 pairs from $C \cdot 1$ and was also assumed to involve a 2:1 frequency ratio. The fourth group involved a same-right plus same-wrong (SR-SW) condition. in which the 20-pair list involved both 10 repeated $R$ items and 10 repeated $W$ items. thus requiring the learning of only 10 items in a 20-pair list and involving a $4: 2$ frequency ratio. The SR-SW condition was included to determine whether the total number of $W$ items had any effect on speed of learning. as compared to the SR condition. Frequency theory thus predicts the orerall superiority of the SR condition. While predicting a null difference between $C \cdot 1$ and $C \cdot 2$. if the length of the list is unimportant. since both control conditions involve a 2:1 frequency ratio. In addition. if the relative frequency ratio between $\mathrm{R}$ and $\mathrm{W}$ items is more important than the absolute frequency accrual. the SR.SW. C-1. and C-2 conditions should not differ. but if the degree of absolute frequency accrual is more important. the SR-SW condition should be superior to the two control conditions which involve lower and identical relative frequency atios.

\section{METHOD}

Lists

The materials of Group C-1 and SR ware evattl identical to thox wed in the Lhitrund et ai 11966, study. The list for the SR-SW condition "is constructed by randomly choosing $10 \mathrm{R}$ item, and $111 \mathrm{~W}$ item, from the list of Condition $C-1$. These item were then paired randomly and re-paired to form a 20-pair list in which each $\mathrm{R}$ item apteared in two different pairs and each W item appeared in two different pairs. The list of Condition C-? was formed by randomly choosing 10 pairs of words from the C -1 list. All list items canie from either the Russell \& Jenkins (1954) or the Palermo \& Jenkins (1964) norms and involved no associates in common according to these norms.

\section{Design and Procedures}

The design was a 4 by 6 factorial. with the four different groups defined above and six trials per group. The experimental procedure followed closely that of Ekistrand et al. including group testing sessions. The materials were presented via the study-test method. With a tape recorder at a $3: 3-\mathrm{sec}$ rate and with a 6-sec intertrial interval. The $\mathrm{S} s$ were given a sheet of paper with two columns of blanks. If the word that was pronounced first on test trials was believed to be the correct item. S was instructed to place a check in the first column. If the word that was pronounced second was believed to be correct. S placed a check in the second column. On study trials. both members of the pairs were pronounced from the tape and then the correct member was pronounced (e.g.. needle-sweet. needle is correct). This was done to ensure a frequency differential in favor of the correct item for each trial. Four independent random orders were used for study and test trials and the temporal position of the $\mathrm{R}$ item was randomized to minimize temporal cues relating to which item was pronounced first or second.

\section{Subjects}

The 100 Ss were introductory psychology students from the Lniversity of Oklahoma. who participated for extra credit. S: were tested in groups of 7-12. The Ss signed up for a particular time. and the list conditions were assigned randomly to the different groups testing sessions. With the stipulation that each condition be run at least once in the morning and once in the afternoon

\section{RESULTS AND DISCUSSION}

The 4 by 6 factorial anaiysis of variance on the proportion of errors to the base of opportunities over the six trials produced significant effects for the groups. $F(3.96)=19.52 . p<.001$. trials. $F(5.480)=44.67$. $p<.001$. and the interaction. $F(15.480)=2.24$. $\mathrm{p}<.005$. The analysis was conducted upon error scores converted to proportions to the base of opportunities rather than total errors. since Group C. 2 had less total opportunity for errors than the three 20-pair groups. The mean proportions $(\mathrm{X}=25)$ for the groups were .027 (SR). .035 (SR-SW). $.047 \quad$ (C-2). and .111 (C-1. Newman-Keuls tests indicated that the C-2. SR-SW. and SR groups all differed significantly $(p<.05)$ from Group C.1. but not froril each other. Thus. Group SR. with a 4:1 frequency ratio and $10 \mathrm{R}$ items to be learned. was not superior to either Group SR-SW or Group C.?. both of which also involved 10 items to be learned but had smaller relative frequency differentials of $t: 2$ and 2:1. respectively. On the other hand. a 20-pair list with a 2:1 relative frequency ratio (Group C-1) was significantly $(p<.05)$ more difficult than Group C with 10 pairs and the same frequency ratio.

Figure 1 depicts the significant Groups by Trials 
interaction. Groups SR. SR-SW, and C.2 differed significantly $(p<.05)$ from Group $C-1$ on all trials. while Groups SR. SR-SW and C.2 did not differ from each other on Trials 2-6. On Trial 1. the SR group was significantly superior to both SR-SW and C-2. as well as C-1. Its superiority both to Group SR-SW. with 10 repeated $R$ items among 20 pairs, and to Group C.?. with only 10 pairs. suggests that the more efficient Trial 1 performance may be due to a higher frequency differential. However. the importance of the higher frequency ratio apparently becomes diminished with increasing trials. consistent with the Weber law analogy' (Ekstrand et al. 1966). while the influence of the number of pairs to be learned becomes greater as base frequency accumulates, as suggested by the null differences among these three groups on Trials 2-6. This interpretation must be made with caution. however, since error rates for all three groups were quite minimal on the later trials.

In general, the results support the conclusion that the number of different $\mathrm{R}$ items to be discriminated is a more important determinant of VD performance than the number of pairs to be learned. This conclusion is supported by the joint evidence that (1) Groups SR: SR-SW and C-2. each involving 10 different $R$ items but with differences in the total number of pairs, did not differ significantly on any of the six trials, while (2) Condition $\mathrm{C}-1$. with 20 different $\mathrm{R}$ items among 20 pairs. was significantly more difficult on all six trials than Condition C.2. with $10 \mathrm{R}$ items in 10 pairs. While this general conclusion might be mitigated if interitem associations increased proportionately with list length. thereby increasing difficulty, this qualification seems unnecessary in view of the marked differences on the first test trial. where the influence of interitem association build-up would be expected to be minimal. In fact. the magnitude of the differences in the proportion of errors on Trial 1 between the 10-pair and 20-pair lists of the present experiment was approximately $7 \%$, exactly the same as the difference in percent of correct responses reported by Underwood et al for Trial 1. contrasting 15-and 45-pair lists under the study-test method. If interitem associations were a greater source of confounding with the present high-frequency words, as opposed to the low-frequency materials used by Underwood et al. the magnitude of first-trial percentage differences would be expected to be considerably higher, rather than the same as those reported by Underwood et al.

The superiority of the 20-pair SR group to the 20-pair control group in the Ekstrand et al study, on the basis of the present results. may have been due at least in part to the fewer number of $R$ items to be learned and not entirely to differences in the magnitude of the differential frequency cue. It is conceivable that a list involving only 10 distinctive $R$ items to be learned among 20 pairs (i.e.. Condition SR) could result in early superiority as a result of S's consciously applying a

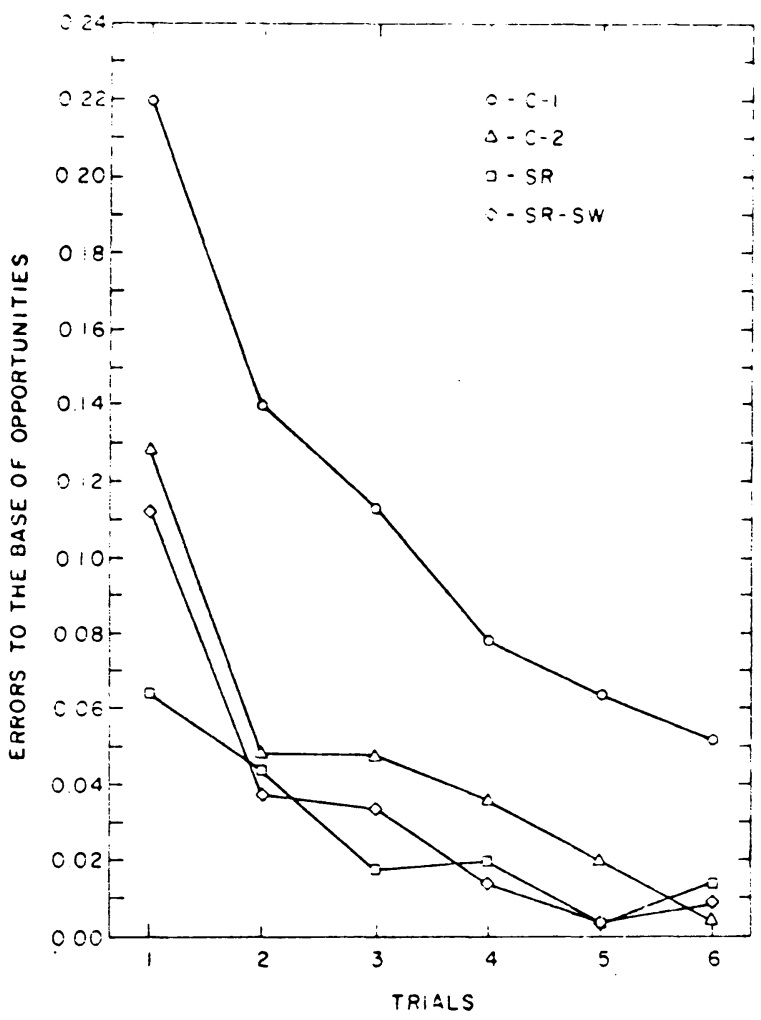

Fig. 1. The mean proportion of errors to the base of opportunities for each trial for each of the four treatment conditions.

higher-order rule, such as "select the repeated items." In the 10-pair control list of the present experiment. however. frequency units acrue so rapidly to the $\mathrm{R}$ item at a 2:1 ratio that the advantage gained by application of such a higher-order rule in Group SR may be mitigated by the strength of a Rule 1 (Ekstrand et al. 1966) strategy of selecting the relatively more frequent item in Group C.2. Differences in rate of acquisition of the 10-pair vs a 20-pair control list in the present study. however, cannot be attributed to differential frequency unit accruals or to differential opportunity for the application of higher-order rules. and are therefore most likely explained by differences in the information processing and retrieval loads associated with the differential number of $\mathrm{R}$ items to be learned.

\section{REFERENCES}

Ekstrand. B. R., Wallace, W. P., \& Underwood. B. J. A frequency theory of verbal discrimination learning. Psychological Review, 1966, 73, 566-578.

Palermo, D. S., \& Jenkins, J. J. Word association norms: Grade school through college. Minneapolis: University of Minnesota Press, 1964 .

Russell, W. A., \& Jenkins, J. J. The complete Minnesota word norms for responses to 100 words from the Kent-Rosanof Word Association Test. Technical Report No. 11. University of Minnesota. Contract Nonr N8 ONR-66216. Office of Naval Research, 1954.

Underwood, B. J., Shaughnessy, J. J.. \& Zimmerman. J. List length and methods of presentation in rerbal discrimination learning with further evidence on retroaction. Journal of Experimental Psychology, 1972, 93, 181-187.

(Received for publication July 5. 1973.) 